\title{
- \\ Successful pharmacotherapy for multiple acute decompensation events in a cirrhotic patient with acute-on-chronic liver failure: A case report

\author{
Xiangbo Xu' ${ }^{1,2 \#}$, Zhaohui Bai ${ }^{1,2 \#, ~ Q i n g c h u n ~ Z h a o ~}{ }^{2 \#}$, Hongyu Li ${ }^{1}$, Qiang Shi ${ }^{1}$, \\ Jiao Deng ${ }^{1}$, Jingqiao Zhang ${ }^{1}$, Xiaozhong Guo ${ }^{1 *}$, Xingshun $\mathbf{Q i}^{1 *}$ \\ 'Department of Gastroenterology, General Hospital of Shenyang Military Area, Shenyang 110840, \\ Liaoning Province, China;
} \\ ${ }^{2}$ Postgraduate College, Shenyang Pharmaceutical University, Shenyang 110016, Liaoning Province, China. \\ ABSTRACT \\ Acute-on-chronic liver failure (ACLF) is a potentially lethal syndrome, which is characterized by an acute deterioration of liver function in patients with chronic liver diseases. The present paper reported that an alcoholic cirrhotic patient with ACLF developed septic shock, hydrothorax, ascites, hepatic encephalopathy, acute kidney injury, and acute upper gastrointestinal bleeding at the same hospitalization and was successfully rescued by pharmacotherapy alone without any invasive intervention.
}

"Co-first authors

${ }^{*}$ Co-corresponding authors.

Address for Correspondence:

Prof. Xiaozhong Guo, Department of

Gastroenterology, General Hospital of

Shenyang Military Area, No. 83 Wenhua

Road, Shenyang 110840, Liaoning

Province, China

E-mail: guo_xiao_zhong@126.com

Dr. Xingshun Qi, Department of

Gastroenterology, General Hospital of

Shenyang Military Area, No. 83 Wenhua

Road, Shenyang 110840, Liaoning

Province, Chin

E-mail: xingshunqi@126.com

\begin{tabular}{|l|}
\hline Access this article online \\
Website: \\
www.intern-med.com \\
\hline DOI: \\
10.2478/jtim-2018-0035 \\
\hline Quick Response Code: \\
\hline \\
\hline
\end{tabular}

Key words: acute-on-chronic liver failure, liver cirrhosis, organ failure, bleeding, pharmacotherapy

\section{INTRODUCTION}

Acute-on-chronic liver failure (ACLF) refers to an acute deterioration of liver dysfunction in patients with chronic liver diseases or liver cirrhosis. It has a dismal prognosis with 28 -day mortality rate of $\geq 15 \% \cdot{ }^{[1]}$ ACLF may occur in the setting of infection, gastrointestinal bleeding, and alcoholic hepatitis. ${ }^{[2,3]}$ Major clinical presentations include sepsis, renal failure, and hepatic encephalopathy. Asian Pacific Association for the Study of the Liver proposed and updated the diagnostic criteria for ACLF in 2009 and 2014, respectively (i.e., serum bilirubin $\geq 5 \mathrm{mg}$ / dl or $85 \mathrm{mmol} / \mathrm{L}$ and coagulopathy, defined as international normalized ratio $(\mathrm{INR}) \geq 1.5$ or prothrombin activity $<40 \%$, complicated by ascites and/or hepatic encephalopathy within 4 weeks in patients who were previously diagnosed or undiagnosed with chronic liver diseases). ${ }^{[4,5]}$ European Association for the Study of the Liver-Chronic Liver Failure Consortium also proposed the definition of ACLF in 2013 according to the presence and number of organ failures, including liver, kidney, cerebral, coagulation, circulation, and respiratory failure. ${ }^{[6]}$ Regardless, early recognition and supportive intensive care are essential for the prevention of irreversible organ failures. ${ }^{[7]}$

Herein, we reported that a cirrhotic patient with ACLF developed multiple acute decompensation events during his hospitalization and was successfully rescued by pharmacotherapy alone.

\section{CASE PRESENTATION}

On January 18, 2018, a 49-year-old male presented with fever, chills, and diarrhea at the Department of Emergency of our hospital. His highest temperature was $40{ }^{\circ} \mathrm{C}$. He had a history of acute pancreatitis and fatty liver 3 years ago. $\mathrm{He}$ had been diagnosed with liver cirrhosis and mild ascites at the first time in December, 2017 and underwent esophageal variceal ligation for acute variceal bleeding at our department on January 2, 2018. He had drunk wine $0.5 \mathrm{~kg} /$ day for more than 10 years. On physical examinations, he was intermittently seditious, confused, and disoriented, his skin was yellowish, shifting 
dullness was positive, and lower limb edema was moderate. His body temperature was $38.7^{\circ} \mathrm{C}$, heart rate was 100 beats per minute, and blood pressure (BP) was 100/54 mmHg. Laboratory tests revealed that white blood cell (WBC) was $6.0 \times 10^{9} / \mathrm{L}$ (reference range: $3.5-9.5 \times 10^{9} / \mathrm{L}$ ), neutrophilic granulocyte percentage (GR\%) was $68.5 \%$ (reference range: 40-75\%), hemoglobin $(\mathrm{Hb})$ was $69 \mathrm{~g} / \mathrm{L}$ (reference range: 130-175 g/L), total bilirubin (TBIL) was $126.8 \mu \mathrm{mol} / \mathrm{L}$ (reference range: $5.1-22.2 \mu \mathrm{mol} / \mathrm{L}$ ), direct bilirubin (DBIL) was $61.5 \mu \mathrm{mol} / \mathrm{L}$ (reference range: $0-8.6 \mu \mathrm{mol} / \mathrm{L}$ ), alanine aminotransferase (ALT) was $37.39 \mathrm{U} / \mathrm{L}$ (reference range: $9-50 \mathrm{U} / \mathrm{L}$ ), aspartate aminotransaminase (AST) was $54.7 \mathrm{U} / \mathrm{L}$ (reference range: $15-40 \mathrm{U} / \mathrm{L}$ ), $\gamma$-glutamyl transpeptidase $(\gamma$-GGT) was $72.05 \mathrm{U} / \mathrm{L}$ (reference range: 10-60 U/L), albumin (ALB) was $29 \mathrm{~g} / \mathrm{L}$ (reference range: $40-55 \mathrm{~g} / \mathrm{L}$ ), blood urea nitrogen (BUN) was $9.77 \mathrm{mmol} / \mathrm{L}$ (reference range: $2.9-8.2 \mathrm{mmol} / \mathrm{L}$ ), creatinine $(\mathrm{Cr})$ was $67.8 \mu \mathrm{mol} / \mathrm{L}(44-133 \mu \mathrm{mol} / \mathrm{L})$, prothrombin time (PT) was $30.7 \mathrm{~s}$ (reference range: $11.5-14.5 \mathrm{~s}$ ), INR was 2.90 , procalcitonin was $25.24 \mathrm{ng} / \mathrm{mL}$ (reference range: 0-0.05 ng/mL), $\mathrm{PaO}_{2}$ was $79 \mathrm{mmHg}$, and $\mathrm{FiO}_{2}$ was $29.0 \%$. Chest and abdomen computed tomography demonstrated pneumonia, hydrothorax, liver cirrhosis, splenomegaly, cholecystitis, ascites, and right renal calculus. Thus, a diagnosis of ACLF grade 1 secondary to infection was considered (Table 1). Child-Pugh score was 12 and model for end-stage liver disease (MELD) score was 25.4. He was treated with ademetionine for liver dysfunction, L-Ornithine-L-Aspartate for hepatic encephalopathy, montmorillonite powder and bifidobacterium lactobacillus tripterygium for diarrhea, and ceftriaxone sodium for infection.

At 12 o'clock on January 19, 2018, the patient was still febrile, the temperature was up to $38.5^{\circ} \mathrm{C}$, BP was
$59 / 23 \mathrm{mmHg}$ and heart rate was 110 beats per minute. He was oliguria with a total of $200 \mathrm{~mL}$ urine drained from urethral catheter during the past 24 hours. Septic shock was considered. Blood culture findings revealed the presence of epidermal staphylococcus and grampositive bacteria. Laboratory tests indicated that WBC was $9.9 \times 10^{9} / \mathrm{L}, \mathrm{GR} \%$ was $84.4 \%$, Hb was $63 \mathrm{~g} / \mathrm{L}$, TBIL was $138.6 \mu \mathrm{mol} / \mathrm{L}$, DBIL was $85.5 \mu \mathrm{mol} / \mathrm{L}$, AST was 40.51 $\mathrm{U} / \mathrm{L}, \gamma$-GGT was $63.38 \mathrm{U} / \mathrm{L}, \mathrm{BUN}$ was $15.76 \mathrm{mmol} / \mathrm{L}$, Cr was $143.56 \mu \mathrm{mol} / \mathrm{L}$, PT was $33.6 \mathrm{~s}$, and INR was 3.25. Acute kidney injury (AKI) stage 2 was considered. ACLF grade 2 was also diagnosed (Table 1). Red blood cells were transfused; dopamine, meropenem, and terlipressin were intravenously infused.

At 19 o'clock on January 19, 2018 and 2 o'clock on January 20, 2018, the patient developed hematemesis twice with a total of $450 \mathrm{~mL}$ dark red colored blood vomited. Esomeprazole, somatostatin, and human albumin were intravenously infused except for nutritional support. On January 21, 2018, the patient became stable, his BP was $86 / 57 \mathrm{mmHg}$, heart rate was 110 beats per minute, and body temperature was $37^{\circ} \mathrm{C}$. Laboratory tests were as follows: WBC was $5.4 \times 10^{9} / \mathrm{L}, \mathrm{GR} \%$ was $78.4 \%$, Hb was $94 \mathrm{~g} / \mathrm{L}, \mathrm{TBIL}$ was $155.9 \mu \mathrm{mol} / \mathrm{L}, \mathrm{DBIL}$ was $90.4 \mu \mathrm{mol} / \mathrm{L}$, AST was $32.52 \mathrm{U} / \mathrm{L}, \gamma$-GGT was $52.3 \mathrm{U} / \mathrm{L}, \mathrm{BUN}$ was $10.27 \mathrm{mmol} / \mathrm{L}$, and $\mathrm{Cr}$ was $42.04 \mu \mathrm{mol} / \mathrm{L}$.

After that, GR\%, C-reaction protein, procalcitonin, Cr, and urine volume gradually improved (Figure 1). He did not develop hematemesis or melena. On January 31, 2018, fecal occult blood test was negative; other laboratory tests showed that WBC was $11.1 \times 10^{9} / \mathrm{L}, \mathrm{GR} \%$ was $65.5 \%$, Hb was $84 \mathrm{~g} / \mathrm{L}$, Crwas $54.56 \mu \mathrm{mol} / \mathrm{L}$, C-reaction protein was $16.5 \mathrm{mg} / \mathrm{L}$ (reference range: $0-8 \mathrm{mg} / \mathrm{L}$ ), and

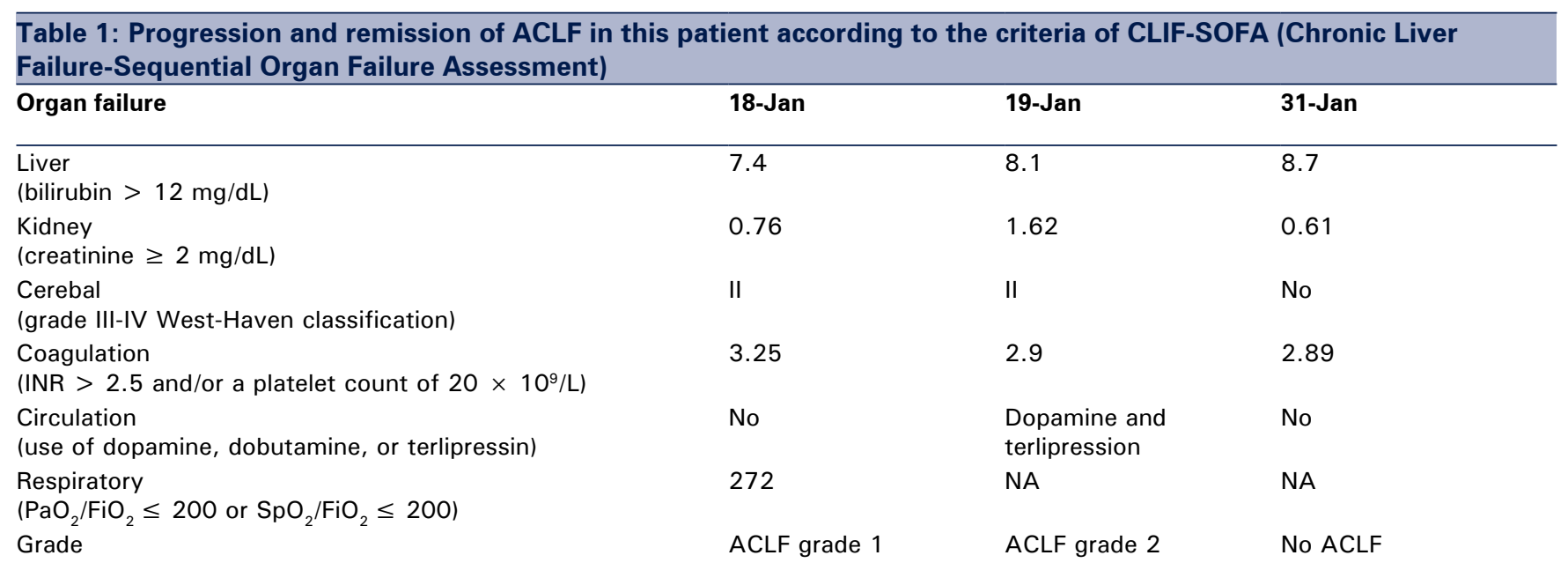

INR: international normalized ratio; ACLF: acute-on-chronic liver failure; NA: not available 
procalcitonin was $0.03 \mathrm{ng} / \mathrm{mL}$. At that time, he did not have ACLF (Table 1). Then, the patient was discharged.

On April 9, 2018, the patient presented with mild distension of abdomen and mild lower limb edema at our department and underwent follow-up laboratory tests. $\mathrm{Hb}$ was $87 \mathrm{~g} / \mathrm{L}$, TBIL was $77.4 \mu \mathrm{mol} / \mathrm{L}$, DBIL was $40.9 \mu \mathrm{mol} / \mathrm{L}$, AST was $54.77 \mathrm{U} / \mathrm{L}$, ALT was $28.05 \mathrm{U} / \mathrm{L}, \gamma$-GGT was $61.07 \mathrm{U} / \mathrm{L}$, ALB was $30.6 \mathrm{~g} / \mathrm{L}$, BUN was $5.36 \mathrm{mmol} / \mathrm{L}$, Cr was 36.79 $\mu \mathrm{mol} / \mathrm{L}$, PT was $19.7 \mathrm{~s}$, and INR was 1.67. Furosemide and spironolactone were prescribed for the management of ascites.

\section{DISCUSSION}

ACLF often has a high short-term mortality in patients with cirrhosis due to the appearance of organ failure, ${ }^{[2,8]}$ which is always associated with a rapid and exaggerated activation of systemic inflammation. ${ }^{[9]}$ Systemic inflammatory response syndrome (SIRS) is defined by the presence of two or more of the following components: temperature $>38^{\circ} \mathrm{C}$ or $<$ $36{ }^{\circ} \mathrm{C}$; heart rate $>90$ beats per minute; respiratory rate $>20$ breaths per minute or $\mathrm{PaCO}_{2}<32 \mathrm{mmHg}$; WBC $<4 \times 10^{9} / \mathrm{L}$ or $>12 \times 10^{9} / \mathrm{L}^{[10]}$ Except for SIRS, this
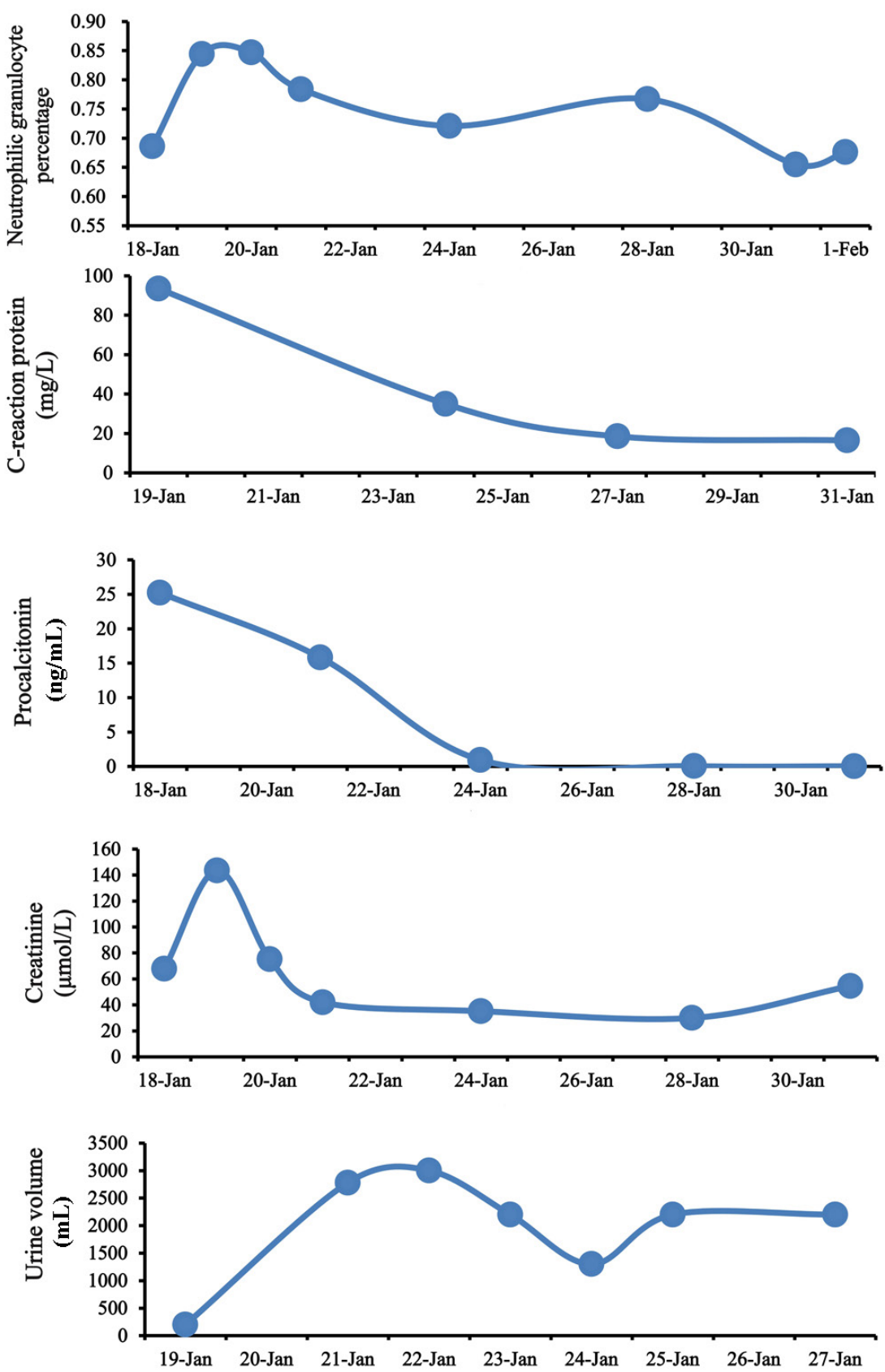

Figure 1: Dynamic changes of neutrophilic granulocyte percentage, C-reaction protein, procalcitonin, creatinine, and urine volume during the hospitalization. 
patient further developed a mean arterial blood pressure of $\leq 65 \mathrm{mmHg}$, suggesting the development of septic shock. ${ }^{[11]}$ Generally, except for prompt settlement of suspected or certain infection, the treatment strategy of septic shock contains immediate intravenous access, fluid administration, vasopressors, and care directing at restoring adequate circulation. ${ }^{[11]}$ In our case, at our admission when SIRS was diagnosed, ceftriaxone sodium was the first-line antibiotics. He rapidly developed septic shock after 1 hour. Thus, meropenem ( $3 \mathrm{~g}$ intravenous infusion per day for 5 days) was selected, which is a drug of empirical treatment for severe septic shock. It is a broad-spectrum antibiotic covering gram-positive bacteria, gram-negative bacteria, and anaerobic bacteria. ${ }^{[12]}$ Infection was successfully and effectively controlled. Indeed, our blood culture findings confirmed the presence of epidermal staphylococcus and gram-positive bacteria, which was sensitive to meropenem.

Renal dysfunction is one of the most common organ failures in patients with $\mathrm{ACLF}^{[13]}$ and is closely related to the presence of bacterial infection and hypovolemia. ${ }^{[14,15]}$ Our case had an increase of $\mathrm{Cr}$ from $67.8 \mu \mathrm{mol} / \mathrm{L}$ to $143.67 \mu \mathrm{mol} / \mathrm{L}$, suggesting the development of AKI stage $2 .^{[16]}$ Additionally, our case also had cirrhosis and ascites without current or recent use of nephrotoxic drugs or macroscopic signs of structural kidney injury. The firstline treatment is terlipressin in combination with human albumin. ${ }^{[17]}$ Recent evidence suggested that continuous intravenous infusion of terlipressin be better tolerated than intravenous boluses. ${ }^{[18]}$ Our case received continuous intravenous infusion terlipressin in combination with human albumin and achieved a complete response that his Cr was significantly decreased.

Upper gastrointestinal bleeding is another decompensation event developing in this cirrhotic patient. Considering that he had a Child-Pugh class C and a MELD score of 25.4, the in-hospital mortality of this patient should be very high. ${ }^{[19,20]}$ Our case had undergone endoscopic therapy for the management of gastroesophageal variceal bleeding before this admission. At this admission, an endoscopic therapy was refused due to his poor status. However, pharmacotherapy with vasoconstrictors is successful for controlling acute bleeding event.

In conclusion, we presented a case with ACLF developing multiple acute decompensation events, which were effectively alleviated by conservative treatment. Certainly, early recognition and intervention should be also emphasized.

\section{Conflict of interest}

None.

\section{Financial support}

None.

\section{REFERENCES}

1. Blasco-Algora S, Masegosa-Ataz J, Gutierrez-Garcia ML, Alonso-Lopez S, Fernandez-Rodriguez CM. Acute-on-chronic liver failure: Pathogenesis, prognostic factors and management. World J Gastroenterol 2015; 21 : 12125-40.

2. Jalan R, Williams R. Acute-on-chronic liver failure: pathophysiological basis of therapeutic options. Blood Purif 2002; 20: 252-61.

3. Moreau R, Arroyo V. Acute-on-Chronic Liver Failure: A New Clinical Entity. Clin Gastroenterol Hepatol 2015; 13: 836-41.

4. Sarin SK, Kumar A, Almeida JA, Chawla YK, Fan ST, Garg H, et al. Acute-on-chronic liver failure: consensus recommendations of the Asian Pacific Association for the study of the liver (APASL). Hepatol Int 2009; 3: 269-82.

5. Sarin SK, Kedarisetty CK, Abbas Z, Amarapurkar D, Bihari C, Chan AC, et al. Acute-on-chronic liver failure: consensus recommendations of the Asian Pacific Association for the Study of the Liver (APASL) 2014. Hepatol Int 2014; 8: 453-71.

6. Kim TY, Kim DJ. Acute-on-chronic liver failure. Clin Mol Hepatol 2013; 19: 349-59.

7. Asrani SK, Simonetto DA, Kamath PS. Acute-on-Chronic Liver Failure. Clin Gastroenterol Hepatol 2015; 13: 2128-39.

8. Peng Y, Qi X, Tang S, Deng H, Li J, Ning Z, et al. Child-Pugh, MELD, and ALBI scores for predicting the in-hospital mortality in cirrhotic patients with acute-on-chronic liver failure. Expert Rev Gastroenterol Hepatol 2016; 10: 971-80.

9. Wasmuth HE, Kunz D, Yagmur E, Timmer-Stranghöner A, Vidacek $\mathrm{D}$, Siewert $\mathrm{E}$, et al. Patients with acute on chronic liver failure display "sepsis-like" immune paralysis. J Hepatol 2005; 42: 195-201.

10. American College of Chest Physicians/Society of Critical Care Medicine Consensus Conference: definitions for sepsis and organ failure and guidelines for the use of innovative therapies in sepsis. Indian J Crit Care Med 1992; 20: 864-74.

11. Seymour CW, Rosengart MR. Septic Shock: Advances in Diagnosis and Treatment. JAMA 2015; 314: 708-17.

12. Wiseman LR, Wagstaff AJ, Brogden RN, Bryson HM. Meropenem. A review of its antibacterial activity, pharmacokinetic properties and clinical efficacy. Drugs 1995; 50: 73-101.

13. Olson JC, Wendon JA, Kramer DJ, Arroyo V, Jalan R, Garcia-Tsao G, et al. Intensive care of the patient with cirrhosis. Hepatology 2011; 54: 1864-72.

14. Martín-Llahí M, Guevara M, Torre A, Fagundes C, Restuccia T, Gilabert $\mathrm{R}$, et al. Prognostic importance of the cause of renal failure in patients with cirrhosis. Gastroenterology 2011; 140: 488-96 e4.

15. Alam A, Chun Suen K, Ma D. Acute-on-chronic liver failure: recent update. J Biomed Res 2017; 31: 283-300.

16. Angeli P, Gines P, Wong F, Bernardi M, Boyer TD, Gerbes A, et al. Diagnosis and management of acute kidney injury in patients with cirrhosis: revised consensus recommendations of the International Club of Ascites. Gut 2015 64: 531-7.

17. Pericleous M, Sarnowski A, Moore A, Fijten R, Zaman M. The clinical management of abdominal ascites, spontaneous bacterial peritonitis and hepatorenal syndrome: a review of current guidelines and recommendations. Eur J Gastroenterol Hepatol 2016; 28: e10-8.

18. Cavallin M, Piano S, Romano A, Fasolato S, Frigo AC, Benetti G, et al. Terlipressin given by continuous intravenous infusion versus intravenous boluses in the treatment of hepatorenal syndrome: A randomized controlled study. Hepatology 2016; 63: 983-92.

19. Peng Y, Qi X, Dai J, Li H, Guo X. Child-Pugh versus MELD score for 
predicting the in-hospital mortality of acute upper gastrointestinal bleeding in liver cirrhosis. Int J Clin Exp Med 2015; 8: 751-7.

20. Peng Y, Qi X, Guo X. Child-Pugh Versus MELD Score for the Assessment of Prognosis in Liver Cirrhosis: A Systematic Review and Meta-Analysis of Observational Studies. Medicine 2016; 95: e2877.
How to cite this article: Xu X, Bai Z, Zhao Q, Li H, Shi Q, Deng J, et al. Successful pharmacotherapy for multiple acute decompensation events in a cirrhotic patient with acute-on-chronic liver failure: A case report. J Transl Intern Med 2018; 6: 189-93. 